Journal of Research in Nursing

Vol. 3, No. 1, 2017

Print ISSN 2244-2723

University of Cebu

Cebu City, Cebu, Philippines

\title{
Socio-cultural Dimensions in Treatment and Compliance of Type 2 Diabetics
}

\author{
Mila E. Marikit \\ Mauro Allan P. Amparado
}

\section{Abstract}

The study determined the Socio-cultural dimensions in treatment and compliance of type 2 diabetics of Visayas Community Medical Center, Cebu City, Cebu, Philippines. Specifically, the study ascertained the: profile of the patients in terms of age, gender, civil status, monthly income, and highest educational attainment; level of the socio-cultural dimension in the treatment of patients in terms of kinship and social system, cultural factors, economic factors, and educational factors; level of compliance of the patients in terms of diet, exercise, medication, and blood glucose monitoring.

Moreover, the study also determined the relationships between the respondents: profile and level of socio-cultural dimensions; profile and level of compliance; and socio-cultural dimensions in treatment and level of compliance.

The study utilized the descriptive-correlational design. The study was conducted at a 200-bed capacity hospital in Cebu City, Cebu, Philippines. There were 42 diabetic patients involved in the study. The researchers used a researcher-made questionnaire. 
Majority of the patients were 55-59 years old, female, married, with income ranging from 10,001 to 20,000 Philippine pesos, and college level. They seldom presented the socio-cultural dimensions and were less compliant on exercise and blood glucose monitoring.

In conclusion, the profile of the diabetic patients has no significant relationship with socio-economic dimensions, and level of compliance. Moreover, socio-economic dimensions and level of compliance are independent from each other.

Recommended citation: Marikit, Mila E. \& Amparado, M. A. P. (2017). Socio-cultural dimensions in treatment and compliance of type 2 diabetics. Journal of Research in Nursing, 3(1), 40-49. 